pulse, BP and baseline bloods (FBC, U\&Es, Clotting, ABGs, G\&S) monitored. Checking of capillary refill time (13.8\%), administration of high-flow oxygen $(12.5 \%)$, blood cultures $(87.5 \%)$, electrocardiograms $(37.5 \%)$ and fluid balance monitoring (56.3\%-81.3\%) need to be performed more frequently. 16 patients had SPE. Baseline bloods (FBC, U\&Es, urate, LFTs \& G\&S), administration of ranitidine and catheterisation were performed in all patients. Of concern are: checking of clotting screen (87.5\%), blood pressure monitoring after administration of antihypertensives (33.3\%-46.2\%) and observations after Magnesium sulphate prescribing (25\%). 37 patients had $\mathrm{PPH}>1.5 \mathrm{~L}$. Measures with $100 \%$ compliance were: the 'ABC' cheque, administering IV fluids and measuring FBC. Weighing blood loss, establishing intravenous access and administration of highflow oxygen and warmed fluids $(32.4 \%-54 \%)$ need to be performed more often.

Conclusion Many aspects of the guidelines are adhered to, but areas of concern must be improved in order to optimise patient care and outcome.

\section{PM.16 ULTRASOUND COLOUR-FLOW DOPPLER IN INITIAL ASSESSMENT OF MORBIDLY ADHERENT PLACENTA FOLLOWED BY SELECTIVE MR IMAGING: A CASE SERIES}

doi:10.1136/archdischild-2013-303966.101

LJ Scarrott, OA Jibodu, U Rajesh. York Teaching Hospital, York, UK

Morbidly adherent placenta (MAP) is the abnormal attachment of the placenta to the uterine wall in which trophoblastic cells invade the uterine tissues. MAP is rare, affecting 1 in 2500 pregnancies $^{1}$, however it is associated with high feto-maternal morbidity and mortality ${ }^{2}$. Previous caesarean section is a major risk factor for development of $\mathrm{MAP}^{3}$, and complicates $24 \%$ of cases of placenta praevia after one prior caesarean section ${ }^{4}$. With the current trend of increasing caesarean section rates ${ }^{5}, \mathrm{MAP}$ will pose significant obstetric problems in the future.

Antenatal diagnosis of MAP has been shown to reduce maternal morbidity ${ }^{6}$. Recent guidance from the National Institute for Clinical Excellence suggests that in cases where there is suspicion of MAP, colour-flow Doppler ultrasound should be used as a first line diagnostic tool ${ }^{7}$. Presence of irregular lacunae within the placental architecture and loss of the clear space in the retroplacental plane are considered to be useful diagnostic criteria in ultrasound imaging of $\mathrm{MAP}^{8}$. Where such ultrasound changes are found, magnetic resonance imaging (MRI) can then be considered to confirm diagnosis and evaluate the extent of invasion which would aid management planning ${ }^{6}$.

We present a case series of 6 patients presenting to York Teaching Hospital in whom MAP was queried on the basis of previous caesarean section, placental localisation scan or clinical presentation. We discuss the role of colour-flow Doppler ultrasound in the initial assessment of suspected MAP followed by selective use of MRI.

\section{REFERENCES}

1. Committee on Obstetric Practice. ACOG committee opinion. Placenta Accreta. Number 266, January 2002. American College of Obstetricians and Gynecologists. Int J Gynaecol Obstet 2002;77: 77-8.

2. Centre for Maternal and Child Enquiries (CMACE). Saving Mothers' Lives: reviewing maternal deaths to make motherhood safer: 2006-08. The Eighth Report on Confidential Enquiries into Maternal Deaths in the United Kingdom. BJOG 2011; 118 (Suppl. 1):1-203.

3. Placenta accreta: Pathogenesis of a $20^{\text {th }}$ century iatrogenic uterine disease. Jauniaux E, Jurkovic D Placenta, April 2012, vol./is. 33/4(244-51), 1532-3102.

4. Placenta praevia/accreta and prior caesarean section. Clark SL, Koonings PP, Phelan JP. Obstet Gynecol 1985;66:89-92.

5. Royal College of Obstetrics and Gynaecology Clinical Effectiveness Support Unit. The national sentinel caesarean section audit report London: RCOG Press, 2001.
6. Effect of predelivery diagnosis in 99 consecutive cases of placenta accreta Warshak CR, Ramos GA, Eskander R, Benirschke K, Saenz CC, Kelly TF, Moore TR, Resnik R. Obstet Gynecol. 2010;115(1):65-9.

7. National Institute for Health and Clinical Excellence 2011. Caesarean Section. CG132. London: National Institute for Health and Clinical Excellence.

8. Role of three-dimensional power Doppler in the antenatal diagnosis of placenta accreta: comparison with grey-scale and colour Doppler techniques. Shih JC, Palacios JM, Su YN, Shyu MK, Lin CH, Lin SY, et al, Ultrasound Obstet Gynecol 2009;33:193-203.

\section{PM.17 IMPACT OF MATERNAL OBESITY ON ACCURACY OF SONOGRAPHIC FETAL WEIGHT ESTIMATION IN IUGR}

doi:10.1136/archdischild-2013-303966.102

FCody, J Unterscheider, S Daly, MP Geary, MM Kennelly, FM McAuliffe, K O'Donoghue, A Hunter, JJ Morrison, G Burke, P Dicker, EC Tully, FD Malone. Perinatal Ireland Research Consortium, Dublin, Ireland

Objective The objective of this analysis, as part of the multicentre prospective PORTO Trial, was to determine whether increasing maternal BMI decreases the accuracy of sonographic fetal weight estimation in IUGR pregnancies.

Study design The PORTO Trial recruited 1,118 consecutive ultrasound-dated singleton IUGR pregnancies, defined as EFW $<10^{\text {th }}$ centile. Maternal BMI was recorded at booking and divided into 4 subcategories. Accuracy of fetal weight assessment was defined as difference between EFW within 2 weeks of delivery and actual birthweight.

Results Of the 1,076 recruited patients with complete records, $693(64 \%)$ were of normal weight (BMI < 25), 258 (24\%) were overweight (BMI 25-30), 93 (9\%) were obese class I (BMI 30-35) and 32 (3\%) were obese class II (BMI 35-40) (Table 1). Overall, fetal weight estimation prior to delivery was within $6 \%$ of respective birthweight. EFW was not influenced by increasing maternal BMI and EFW accuracy was only marginally better in normal weight mothers. Greater BMI was associated with earlier gestational age at delivery.

Conclusion These data show that ultrasound is reliable in the assessment of fetal weight in IUGR in the presence of increased maternal BMI.

Abstract PM.17 Table 1 Outcomes for BMI Categories.

\begin{tabular}{llllll}
\hline & $\begin{array}{l}\text { Normal } \\
\text { weight }\end{array}$ & Overweight & $\begin{array}{l}\text { Obese } \\
\text { Class I }\end{array}$ & $\begin{array}{l}\text { Obese } \\
\text { Class II }\end{array}$ & p-value \\
\hline $\begin{array}{l}\text { Mean GA at delivery } \\
\text { (weeks) }\end{array}$ & 38.1 & 37.5 & 37.2 & 35.5 & $<0.0001$ \\
$\begin{array}{l}\text { Birthweight (g) } \\
\text { EFW (<2 weeks }\end{array}$ & 2543 & 2473 & 2414 & 1989 & 0.0055 \\
$\begin{array}{l}\text { of delivery) } \\
\text { Median \% difference }\end{array}$ & $6.3 \%$ & $6.4 \%$ & $5.9 \%$ & $6.6 \%$ & 0.9828 \\
\hline
\end{tabular}

Note: P-value compares $\mathrm{BMl}<25$ to $\mathrm{BMl}>25$

\section{PM.18 MATERNAL RESTING PERIPHERAL BLOOD FLOW AND TISSUE OXYGENATION IN PREGNANCIES COMPLICATED WITH PRE-ECLAMPSIA AND IUGR}

doi:10.1136/archdischild-2013-303966.103

1,2 $\mathrm{VL}$ Karanam, ${ }^{1} \mathrm{NM}$ Page, ${ }^{1,2} \mathrm{~N}$ Anim-Nyame. ${ }^{1}$ Kingston Umiversity, London, UK; ${ }^{2}$ Kingston Hospital, London, UK

Background Pre-eclampsia is characterised by hypertension and proteinuria and associated with systemic hypoperfusion of multiple maternal organs. Intrauterine growth restriction (IUGR) is a recognised complication of pre-eclampsia and the two conditions 
share the same primary pathology. The clinical features of preeclampsia are consistent with hypoxia and the changes in oxygen delivery and consumption indices in women with severe disease are similar to that observed in distributive shock. However, so far there are no studies done on maternal tissue oxygenation levels in pregnancies complicated by pre-eclampsia and IUGR.

Methodology Women in their third trimester with pre-eclampsia, IUGR and normal pregnancy ( $\mathrm{n}=16,6,16$ respectively) were recruited for the study. Filtrass strain gauge plethysmography was used to compare calf blood flow and Mediaid iPOX pulse oximeter was used to compare the oxygenation in the three groups.

Results The resting peripheral blood flow was significantly reduced in pre-eclampsia group compared to normal pregnancy group (mean \pm SEM $[2.1 \pm 0.22$ vs.1.01 \pm 0.1$], p=0.003$ ), however no change was demonstrated in IUGR group compared to normal pregnancy group (mean \pm SEM $[2.1 \pm 0.22$ vs.1.9 \pm 0.5$], p=0.92$ ). No significant difference was noted in maternal tissue oxygenation between the normal pregnancy, pre-eclampsia and IUGR groups (mean \pm SEM $[97.13 \pm 0.4,96.69 \pm 0.33,97.83 \pm 0.47$ respectively $\}$ $\mathrm{p}=0.26$ ). No correlation was found between blood flow and tissue oxygenation.

Conclusion This study demonstrated that there is reduced resting peripheral blood flow in women with pre-eclampsia but not in IUGR and the reduction in blood flow in pre-eclampsia is not associated with changes in tissue oxygenation.

\section{PM.19 WITHDRAWN BY AUTHOR}

\section{PM.20 THYROID HORMONE ACTION IN THE DECIDUA DURING HUMAN PREGNANCY}

doi:10.1136/archdischild-2013-303966.104

${ }^{1}$ E Vasilopoulou, ' $\mathrm{LS}$ Loubiere, ${ }^{2} \mathrm{GE}$ Lash, ${ }^{30} \mathrm{O}$ Ohizua, ${ }^{1} \mathrm{JA}$ Franklyn, ${ }^{1} \mathrm{MD}$ Kilby, ${ }^{1} \underline{\mathrm{SY}}$ Chan. 'University of Birmingham, Birmingham, UK; ${ }^{2}$ Newcastle University, Newcastle-UponTyne, UK; ${ }^{3}$ Walsall Hospitals NHS Trust, Walsall, UK

Introduction Maternal thyroid dysfunction is associated with complications of malplacentation including miscarriages and preeclampsia. We hypothesise that thyroid hormones (TH) play an important role within human decidua in regulating placentation.

Methods Deciduas from human pregnancy were obtained from $1^{\text {st }}$ (8-11 weeks) and $2^{\text {nd }}$ trimester (12-20 weeks) surgical terminations of pregnancy. Primary cultures of total decidual cells (TDC), and immunomagnetic bead isolated populations of stromal-enriched $\left(\mathrm{CD} 10^{+\mathrm{ve}}\right)$ and stromal-depleted $\left(\mathrm{CD} 10^{-\mathrm{ve}}\right)$ cells, uterine natural killer cells (uNKs; $\left.\mathrm{CD}^{+6^{+v e}}\right)$ and macrophages $\left(\mathrm{CD} 14^{+\mathrm{ve}}\right)$ were treated with T3 $(0.10,100 \mathrm{nM})$. Assessments were made of cell viability (MTT assay), cytokine and angiogenic growth factor secretion (immunomediated assay) and the effects of decidual cell-conditioned media on extravillous trophoblast (EVT) invasion through Matrige ${ }^{\circledR}$.

Results Immunohistochemistry showed the expression of $\mathrm{TH}$ transporters (MCT8, MCT10) and receptors (TR $\alpha 1$, TR $\beta 1)$ required for TH-responsiveness in uNKs and macrophages from early gestation. The viability of TDC and cell isolates were unaffected by T3. In $1^{\text {st }}$ trimester, T3 reduced IL-10 secretion by TDC and CD10-ve cells $(p<0.01)$, and reduced GM-CSF, IL-10, IL-1 $\beta$, IL-6, MCP-1 by macrophages $(p<0.01)$. In $2^{\text {nd }}$ trimester, T3 increased IL-10 by TDC $(p<0.01)$ and reduced IL-10 by uNKs $(p<0.001)$. T3 increased VEGF secretion by $1^{\text {st }}$ trimester $\mathrm{uNKs}(\mathrm{p}<0.05)$, and angiopoietin-2 by $2^{\text {nd }}$ trimester TDC and uNKs $(p<0.05)$. Conditioned media from T3-treated TDC and macrophages did not alter EVT invasion compared to untreated controls.

Conclusion TH regulate decidual cytokine and angiogenic growth factor secretion in a cell-specific and gestation-dependent manner. The summation of $\mathrm{TH}$ effects upon the secretome do not affect EVT invasion.

\section{PM.21 COMPLIANCE WITH POSTNATAL THROMBOPROPHYLAXIS}

doi:10.1136/archdischild-2013-303966.105

${ }^{2}$ F Ayim, 'DA Banfield, ${ }^{2} \mathrm{JC}$ Girling, L Page. ${ }^{1}$ Imperial College London, London, UK; ${ }^{2}$ West Middlesex University Hospital, Middlesex, UK

Background Venous thromboembolism (VTE) is the $3^{\text {rd }}$ leading cause of maternal death in the UK ${ }^{1}$. In order to minimise VTE risk in the postnatal period, we introduced a new scoring system in June 2011, based on RCOG guidelines ${ }^{2}$. Every woman's VTE risk is scored, and those who meet predetermined criteria are discharged on a seven days (7/7) or six weeks (6/52) course of low molecular weight heparin $(\mathrm{LMWH})$. There were concerns regarding patient compliance and so a survey was conducted to explore this.

Method Pharmacy data identified 113 postnatal women who were discharged in November 2011 on LMWH. A telephone survey in February 2012 assessed understanding of the need for LMWH, and compliance.

Results 52 women were successfully contacted: 29 had been prescribed a 7/7 course, and 23 a 6/52 course.

- $100 \%$ of women understood the need for LMWH

- $96 \%$ of those on a $7 / 7$ course completed all injections.

- Only $32 \%$ completed the $6 / 52$ course.

We identified reasons for non-compliance and the destination of unused LMWH.

Conclusion Non-compliance has implications for both patient safety and cost. The survey highlighted the importance of effective patient education and identified a need for improved communication between primary and secondary care. A multidisciplinary approach, with all healthcare professionals emphasising the importance of LMWH in the postnatal period may improve long-term compliance. A patient information leaflet has since been introduced.

\section{REFERENCES}

1. Centre for Maternal and Child Enquiries. Saving Mothers' Lives: Reviewing Maternal Deaths to Make Motherhood Safer, 2006-2008. The Eighth Report of the Confidential Enquiries into Maternal Deaths in the United Kingdom. London: CMACE March 2011.

2. Royal College of Obstetricians and Gynaecologists. Green top Guideline No.37a: Reducing the risk of Thrombosis and Embolism during Pregnancy and the Puerperium. November 2009.

\section{PM.22 THE ROLE OF VEGF ${ }_{165}$ B IN TROPHOBLAST SURVIVAL - IMPLICATIONS FOR PRE-ECLAMPSIA PATHOPHYSIOLOGY}

doi:10.1136/archdischild-2013-303966.106

1,2VL Bills, '2DO Bates, 'PW Soothill, 'T Overton. 'St Michael's Hospital, Bristol, UK, ${ }^{2}$ Microvascular Research Laboratories, University of Bristol, Bristol, UK

It is widely accepted that the pathophysiological foundations of pre-eclampsia are laid down in the first trimester, with inadequate invasion of placental trophoblasts into maternal spiral arteries of the uterus, resulting in defective arterial remodelling. The angiogenic VEGF family of glycoproteins are expressed in first trimester trophoblasts and are important factors in placental development, which occurs in a hypoxic $\left(<2 \% \mathrm{O}_{2}\right)$ environment up to $10-12$ weeks and normoxia $\left(>20 \% \mathrm{O}_{2}\right)$ thereafter. First trimester $\mathrm{VEGF}_{165} \mathrm{~b}$ levels are low in women destined to later develop pre-eclampsia, so we investigated whether $\operatorname{VEGF}_{165}$ b plays a role in early trophoblast survival and therefore pre-eclampsia pathophysiology.

Trophoblast cells were cultured in hypoxic and normoxic environments, in the absence and presence of VEGF ${ }_{165} b$ and $a$ VEGF $_{165} b$ blocking antibody clone $56-1$. Cell survival was studied via cytotoxicity experiments. Production of $\mathrm{VEGF}_{165}$ b by trophoblasts was determined via enzyme linked immunoassay (ELISA).

$\mathrm{VEGF}_{165}$ b production by trophoblasts was increased in response to hypoxia (hypoxia: $1812 \pm 33 \mathrm{pg} / \mathrm{ml}$ vs. normoxia: $1407 \pm 95 \mathrm{pg} / \mathrm{ml}$, unpaired t test, $\mathrm{p}=0.016)$, and inhibition of $\mathrm{VEGF}_{165} \mathrm{~b}$ increased 